University of Nebraska - Lincoln

DigitalCommons@University of Nebraska - Lincoln

Nutrition and Health Sciences -- Faculty

Publications

Nutrition and Health Sciences, Department of

2019

\title{
The validity of the EMG and MMG techniques to examine muscle hypertrophy
}

\author{
Ethan C. Hill \\ University of Nebraska-Lincoln, ethan.hill@unl.edu \\ Terry J. Housh \\ University of Nebraska-Lincoln, thoush1@unl.edu \\ Josh L. Keller \\ University of Nebraska - Lincoln, jkeller@unl.edu \\ Cory M. Smith \\ University of Nebraska - Lincoln, cmsmith7@utep.edu \\ Richard Schmidt \\ University of Nebraska-Lincoln, rschmidt1@unl.edu
}

See next page for additional authors

Follow this and additional works at: https://digitalcommons.unl.edu/nutritionfacpub

Part of the Human and Clinical Nutrition Commons, Molecular, Genetic, and Biochemical Nutrition Commons, and the Other Nutrition Commons

Hill, Ethan C.; Housh, Terry J.; Keller, Josh L.; Smith, Cory M.; Schmidt, Richard; and Johnson, Glen O., "The validity of the EMG and MMG techniques to examine muscle hypertrophy" (2019). Nutrition and Health Sciences -- Faculty Publications. 196.

https://digitalcommons.unl.edu/nutritionfacpub/196

This Article is brought to you for free and open access by the Nutrition and Health Sciences, Department of at DigitalCommons@University of Nebraska - Lincoln. It has been accepted for inclusion in Nutrition and Health Sciences -- Faculty Publications by an authorized administrator of DigitalCommons@University of Nebraska Lincoln. 


\section{Authors}

Ethan C. Hill, Terry J. Housh, Josh L. Keller, Cory M. Smith, Richard Schmidt, and Glen O. Johnson 


\title{
The validity of the EMG and MMG techniques to examine muscle hypertrophy
}

\author{
Ethan C. Hill, Terry J. Housh, Joshua L. Keller, \\ Cory M. Smith, Richard J. Schmidt, and \\ Glen O. Johnson
}

\begin{abstract}
Human Performance Laboratory, Department of Nutrition and Health Sciences, University of Nebraska-Lincoln, Lincoln, NE 68505, United States of America
\end{abstract}

Corresponding author - E. C. Hill, email ethan.hill@unl.edu

\section{ORCID}

Ethan C. Hill https://orcid.org/0000-0002-5573-3370

Joshua L. Keller https://orcid.org/0000-0003-0756-9358

Cory M. Smith https://orcid.org/0000-0001-9581-1225

\begin{abstract}
Objective: The purpose of this investigation was to examine the ability of the electromyographic (EMG) and mechanomyographic (MMG) amplitude versus torque relationships to track group and individual changes in muscle hypertrophy as a result of resistance training.

Approach: Twelve women performed four weeks of forearm flexion blood flow restriction (BFR) resistance training at a frequency of three times per week. The training was performed at an isokinetic velocity of $120^{\circ} \cdot \mathrm{s}^{-1}$ with a training load that corresponded to $30 \%$ of concentric peak torque. Muscle hypertrophy was determined using ultrasound-based assessments of muscle cross-sectional area
\end{abstract}

Published in Physiological Measurement 40 (2019), 025009 (11pp). doi 10.1088/1361-6579/ab057e

Copyright (c) 2019 Institute of Physics and Engineering in Medicine. Published by IOP Publishing. Used by permission.

Submitted 1 August 2018; revised 23 January 2019; accepted 8 February 2019; published 28 February 2019. 
from the biceps brachii. Training-induced changes in the slope coefficients of the EMG amplitude and MMG amplitude versus torque relationships were determined from the biceps brachii during incremental (10\%-100\% of maximum) isometric muscle actions.

Main results: There was a significant $(p<0.001 ; d=2.15)$ mean training-induced increase in muscle cross-sectional area from 0 week (mean $\pm S D=5.86 \pm 0.65$ $\left.\mathrm{cm}^{2}\right)$ to 4 weeks $\left(7.42 \pm 0.80 \mathrm{~cm}^{2}\right)$, a significant $(p=0.023 ; d=0.36)$ decrease in the EMG amplitude versus torque relationship (50.70 \pm 20.41 to $43.82 \pm 17.76$ $\left.\mu \mathrm{V} \cdot \mathrm{Nm}^{-1}\right)$, but no significant $(p=0.192 ; d=0.17$ ) change in the MMG amplitude versus torque relationship $\left(0.018 \pm 0.009\right.$ to $\left.0.020 \pm 0.009 \mathrm{~m} \cdot \mathrm{s}^{-2} \cdot \mathrm{Nm}^{-1}\right)$. There was, however, great variability for the individual responses for the EMG and MMG amplitude versus torque relationships.

Significance: The results of the present study indicated that the EMG amplitude, but not the MMG amplitude versus torque relationship was sensitive to mean changes in muscle cross-sectional area during the early-phase of resistance training. There was, however, great variability for the individual EMG amplitude versus torque relationships that limits its application for identifying individual changes in muscle hypertrophy as a result of BFR.

Keywords: resistance training, muscle activation, low-load, blood flow restriction

\section{Introduction}

Moritani and deVries (1979) proposed an electromyographic (EMG) technique called efficiency of electrical activity (EEA) for estimating the relative contributions of neural and hypertrophic adaptations to resistance traininginduced increases in muscle strength. The EEA technique involves plotting EMG amplitude versus force for a series of submaximal and maximal isometric muscle actions prior to and after a resistance training intervention (Moritani and deVries 1979). Theoretically, a training-induced increase in maximal EMG amplitude reflects greater maximal muscle activation as a result of neural adaptations, while a decrease in the EEA slope coefficient reflects hypertrophy because less muscle activation is required to produce a specific level of force. Specifically, Moritani and deVries (1979) suggested that 'the increase in cross-sectional area was highly correlated with the decrease in the EMG slope coefficient... This finding provides further strong support for the concept of (EEA) that the ratio of a given muscle activation level to the force produced reflects not only a genotypic factor... but also a phenotypic factor, i.e. the level of fiber hypertrophy...' (Moritani and deVries 1979, pp 120-2). Moritani and deVries (1979) found that after eight weeks of resistance training neural and hypertrophic adaptations accounted for approximately 15 and $85 \%$ of the increases in isometric strength, respectively. The 
EEA technique of Moritani and deVries (1979) has also been used to examine muscle atrophy (deVries 1968), the time-course of neural versus hypertrophic adaptations to training (Moritani and deVries 1979), and the characteristics of the cross-education effect in both young and elderly subjects (Moritani and deVries 1981).

DeFreitas et al (2012) applied the mathematical model of Moritani and deVries (1979) to the mechanomyographic (MMG) signal to describe the time-course of muscle hypertrophy. Specifically, DeFreitas et al (2012) plotted the MMG amplitude versus force relationships across submaximal intensities of the pretraining maximal voluntary isometric contraction (MVIC) value prior to and after a resistance training intervention. DeFreitas et al (2012) hypothesized that a decrease in the slope coefficient of the MMG amplitude versus force relationship reflected muscle hypertrophy because a fewer number of motor units would be required to produce pretraining force levels. Specifically, 'increased contractile protein content would cause each fiber, and therefore each motor unit, to be able to produce more force. So after the occurrence of skeletal muscle hypertrophy, fewer motor units would be required to produce the same amount of force when compared to before training.' (DeFreitas et al 2012, p 1359). Consistent with this hypothesis, DeFreitas et al (2012) reported that the slope coefficients of the MMG amplitude versus force relationship decreased after four weeks ( 0.0074 to $0.0049 \mathrm{~m} \cdot \mathrm{s}^{-2} \mathrm{~kg}{ }^{-1}$ ) and eight weeks ( 0.0074 to 0.0048 $\mathrm{m} \cdot \mathrm{s}^{-2} \mathrm{~kg}^{-1}$ ) of resistance training and attributed these decreases to muscle hypertrophy. Thus, theoretically, resistance training-induced decreases in the slope coefficients of the EMG amplitude and MMG amplitude versus force relationships reflect muscle hypertrophy. No previous investigations, however, have independently examined the MMG amplitude versus force relationship as an indicator of hypertrophy. Furthermore, little is known regarding the sensitivity of EMG amplitude and MMG amplitude versus force relationships for identifying resistance training-induced hypertrophic adaptations for individual subjects. Therefore, the purpose of this investigation was to examine the ability of the EMG and MMG techniques to track group and individual changes in muscle hypertrophy as a result of resistance training. Based on previous investigations (Moritani and deVries 1979, DeFreitas et al 2012), we hypothesized that there would be decreases in the slope coefficients of the EMG and MMG amplitude versus force relationships for the group data as a result of resistance training and these responses would be consistent with the increases in muscle cross-sectional area. Furthermore, we hypothesized both the EMG amplitude and MMG amplitude versus force relationships would be sensitive to hypertrophic adaptations for individual subjects. 


\section{Methods}

\subsection{Subjects}

Twelve non-resistance trained women volunteered to participate in this investigation ( $n=12$; mean age $\pm S D=22.1 \pm 1.7$ years; body mass $=55.4 \pm$ $5.0 \mathrm{~kg}$; height $=165.9 \pm 5.2 \mathrm{~cm}$ ). These subjects were part of a larger investigation that have been published previously (Hill et al 2018) for purposes unrelated to this study. All subjects were recreationally active at the time of testing, but had not been actively participating in resistance training for at least the past six months. The subjects had no known cardiovascular, pulmonary, metabolic, muscular, and/or coronary heart disease, or regularly used prescription medication. The subjects visited the laboratory on 15 occasions (familiarization, baseline, 13 testing/training visits) within a 5 week period and performed the testing procedures at the same time of day $( \pm 2$ h). The study was approved by the University Institutional Review Board for Human Subjects and all subjects completed a health history questionnaire and signed a written informed consent prior to testing.

\subsection{Procedures}

\subsection{Familiarization}

The first laboratory visit consisted of an orientation session to familiarize the subjects with the testing protocols. During the orientation, subjects performed submaximal and maximal isometric muscle actions as well as submaximal and maximal concentric isokinetic muscle actions of the forearm flexors at $120^{\circ} \cdot \mathrm{s}^{-1}$. To familiarize the subjects with the training protocols, the subjects also practiced performing concentric isokinetic muscle actions at $30 \%$ of their concentric peak torque. Torque was visually tracked using realtime torque displayed on a computer monitor. In addition, a blood flow restriction (BFR) device (KAATSU Master, Sato Sports Plaza, Tokyo, Japan) was applied to familiarize the subjects with the training procedures. Following the familiarization visit, the subjects completed three testing visits (baseline, 0 week, and 4 week) and 12 training visits (Table 1). The data from the baseline visit was used for reliability purposes.

\subsubsection{Determination of concentric peak torque and MVIC}

During all testing and training visits, the subjects performed a warm-up consisting of 10 submaximal (approximately $50 \%$ effort), concentric-eccentric muscle actions at $120^{\circ} \cdot \mathrm{s}^{-1}$ on the isokinetic dynamometer. On baseline, 0 week, and 4 week testing visit, following the warmup the subjects rested for $5 \mathrm{~min}$ and then randomly performed two pretest concentric peak torque and two MVIC trials. The concentric muscle actions were performed through 
Table 1. Overview of the procedures performed at each testing and training visit.

\begin{tabular}{|c|c|c|c|c|}
\hline Familiarization & Baseline & O week & 12 training sessions & 4 weeks \\
\hline Paperwork & $\begin{array}{l}\text { Determination } \\
\text { of concentric } \\
\text { peak torque } \\
\text { and MVIC }\end{array}$ & $\begin{array}{l}\text { Determination } \\
\text { of concentric } \\
\text { peak torque } \\
\text { and MVIC }\end{array}$ & $\begin{array}{l}75(1 \times 30,3 \times 15) \\
\text { concentric forearm } \\
\text { flexion repetitions at } \\
30 \% \text { of concentric peak } \\
\text { torque performed with } \\
\text { BFR at } 40 \% \text { of arterial } \\
\text { occlusion pressure }\end{array}$ & $\begin{array}{l}\text { Determination of } \\
\text { concentric } \\
\text { peak torque } \\
\text { and MVIC }\end{array}$ \\
\hline $\begin{array}{l}\text { Submaximal and } \\
\text { maximal concentric } \\
\text { and isometric } \\
\text { repetitions }\end{array}$ & $\begin{array}{l}\text { Determination } \\
\text { of BFR target } \\
\text { pressure }\end{array}$ & $\begin{array}{l}\text { Determination } \\
\text { of BFR target } \\
\text { pressure }\end{array}$ & & $\begin{array}{l}\text { MVIC EMG and } \\
\text { MMG amplitude } \\
\text { assessments }\end{array}$ \\
\hline $\begin{array}{l}\text { Concentric } \\
\text { repetitions at 30\% } \\
\text { of concentric } \\
\text { peak torque }\end{array}$ & $\begin{array}{l}\text { MVIC EMG } \\
\text { and MMG } \\
\text { amplitude } \\
\text { assessments }\end{array}$ & $\begin{array}{l}\text { MVIC EMG } \\
\text { and MMG } \\
\text { amplitude } \\
\text { assessments }\end{array}$ & & $\begin{array}{l}\text { Submaximal EMG and } \\
\text { MMG amplitude } \\
\text { assessments } \\
(10 \%-100 \%)\end{array}$ \\
\hline BFR application & $\begin{array}{l}\text { Muscle cross- } \\
\text { sectional area } \\
\text { via ultrasound }\end{array}$ & \multicolumn{2}{|c|}{$\begin{array}{l}\text { Submaximal EMG } \\
\text { and MMG amplitude } \\
\text { assessments } \\
(10 \%-100 \%) \\
\text { Muscle cross-sectional } \\
\text { area via ultrasound }\end{array}$} & $\begin{array}{l}\text { Muscle cross- } \\
\text { sectional area } \\
\text { via ultrasound }\end{array}$ \\
\hline
\end{tabular}

a $120^{\circ}$ range of motion $\left(0-120^{\circ}\right.$ of elbow flexion, where $0^{\circ}$ corresponds to full elbow extension) and the MVIC muscle actions were performed at a joint angle of $45^{\circ}$ at the elbow.

\subsubsection{Concentric training intervention}

The subjects completed four weeks of concentric BFR training at a frequency of three training sessions per week for a total of 12 training sessions. The training interventions consisted of 75 concentric forearm flexion muscle actions performed over four sets $(1 \times 30,3 \times 15)$ and each set was separated by $30 \mathrm{~s}$ of rest. The training intervention was randomly assigned to either the dominant or non-dominant arm. All muscle actions were performed at a velocity of $120^{\circ} \cdot \mathrm{s}^{-1}$ using an isokinetic dynamometer (Cybex 6000, LUMEX, Inc. Ronkonkoma, New York).

\subsubsection{Blood flow restriction (BFR)}

BFR was applied using a $30 \mathrm{~mm}$ wide cuff (KAATSU Master, Sato Sports Plaza, Tokyo, Japan) placed on the most proximal portion of the arm. The cuff pressure was initially applied at $30 \mathrm{~mm} \mathrm{Hg}$ and progressively inflated and deflated over a $60 \mathrm{~s}$ period until the target pressure was reached. Target pressure was calculated at the baseline, 0 week, and 2 week visits as $40 \%$ of the lowest amount of pressure needed to completely occlude the brachial artery as indicated by ultrasound (Loenneke et al 2013, 2016, Counts et al 2016). The cuff remained inflated during the duration of the training bout and was 
deflated immediately after completing the 75 repetitions. The total duration of BFR was approximately five minutes.

\subsubsection{Neuromuscular-based assessments of muscle hypertrophy}

During the baseline, 0 week and 4 week testing visits, pre-gelled surface electrodes (Ag/AgCl, AccuSensor, Lynn Medical, Wixom, MI, USA) were placed in a bipolar arrangement (30 $\mathrm{mm}$ center-to-center) on the biceps brachii muscle of the training arm according to the recommendations of Barbero et al (2012). The reference electrode was placed over the acromion process and prior to each electrode placement, the skin was shaved, carefully abraded, and cleaned with alcohol. The MMG signal was detected using an accelerometer (Entran EGAS FT 10, dimensions: $1.0 \times 1.0 \times 0.5 \mathrm{~cm}$, mass: 1.0 g) that was placed between the proximal and distal EMG electrodes of the bipolar arrangement using double-sided adhesive tape. The raw EMG and MMG signals were digitized at $2000 \mathrm{~Hz}$ with a 32-bit analog-to-digital converter (Model MP150, Biopac Systems, Inc.) and stored in a personal computer (ATIV Book 9 Intel Core i7 Samsung Inc., Dallas, TX) for subsequent analyses. The EMG signals were amplified (gain: $\times 1000$ ) using differential amplifiers (EMG 100, Biopac Systems, Inc., Santa Barbara, CA). The EMG and MMG signals were digitally bandpass filtered (fourth-order Butterworth, zero-phase shift) at $10-500 \mathrm{~Hz}$ and $5-100 \mathrm{~Hz}$, respectively.

To replicate the methods of Moritani and deVries (1979) and DeFreitas et al (2012) the subjects performed incremental isometric muscle actions at $10 \%-100 \%$ of their 0 week MVIC torque in $10 \%$ increments. Each incremental muscle action was performed until target torque was sustained for a period of $3 \mathrm{~s}$ and EMG and MMG signals were simultaneously recorded. The EMG values were expressed as the integral of the time-averaged amplitude value $(\mu \mathrm{V})$ (Basmajian and De Luca 1985) and the amplitude of MMG signals were calculated as the root-mean-square and expressed as $\mathrm{m} \cdot \mathrm{s}^{-2}$ (DeFreitas et al 2011). The subsequent EMG and MMG values were then used to derive the EMG versus torque $\left(\mu \mathrm{V} \cdot \mathrm{Nm}^{-1}\right)$ and $\mathrm{MMG}$ versus torque $\left(\mathrm{m} \cdot \mathrm{s}^{-2} \cdot \mathrm{Nm}^{-1}\right)$ relationships. The same procedures were performed at the 4 week testing visit during which the subjects also performed an additional MVIC muscle action to obtain their 4 week MVIC value.

\subsubsection{Ultrasound-based assessment of muscle hypertrophy}

To examine muscle hypertrophy, ultrasound assessments of muscle crosssectional area were performed prior to each testing visit. Ultrasound images of the trained arms (biceps brachii) were obtained using a portable brightness mode (B-mode) ultrasound-imaging device (GE Logiq, Boston, MA, USA) and a multi-frequency linear-array probe (12L-Rs; $5-13 \mathrm{MHz}$; $38.4 \mathrm{~mm}$ field-of-view). All ultrasound measurements were performed at a sampling rate of $10 \mathrm{MHz}$ and at a gain of $58 \mathrm{~dB}$. Ultrasound images were 


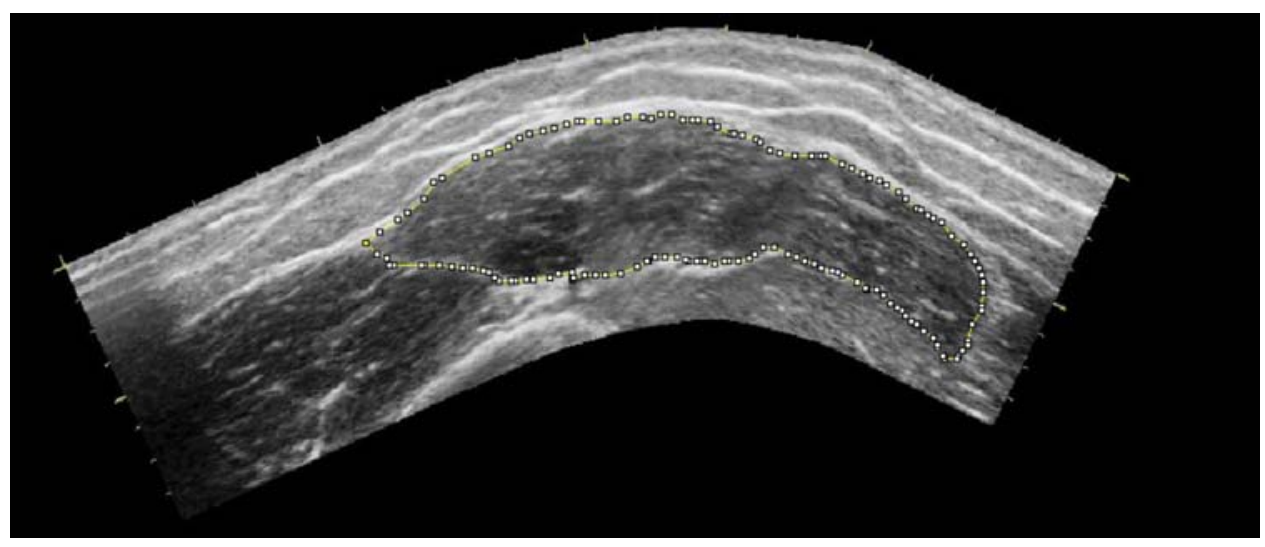

Figure 1. A panoramic ultrasound image of the forearm flexors used to determine muscle cross-sectional area of the biceps brachii muscle. Muscle cross-sectional area was determined by slowly moving the probe from the most medial to the most lateral aspect of the biceps brachii using the panoramic mode on the ultrasound device and derived using the polygon function in ImageJ.

analyzed using ImageJ software (Version 1.47v., National Institutes of Health, Bethesda, MD, USA) and prior to all analyses, images were scaled from pixels to centimeters using the straight-line function in ImageJ. Muscle crosssectional area was determined using the same procedures that we have described previously (Jenkins et al 2015). Briefly, muscle cross-sectional area was assessed at $66 \%$ of the distance from the medial acromion of the scapula to the fossa cubit. Muscle cross-sectional area was determined by slowly moving the probe from the most medial to the most lateral aspect of the biceps brachii using the panoramic mode on the ultrasound device and derived using the polygon function in ImageJ (Figure 1). Great care was taken to ensure that consistent, minimal pressure was applied with the probe to limit compression of the artery. To enhance acoustic coupling and reduce near field artifacts, a generous amount of water-soluble transmission gel was applied to the skin prior to each measurement.

\subsection{Data analysis}

\subsubsection{Reliability}

Test-retest reliability for concentric peak torque, MVIC, muscle cross-sectional area, EMG amplitude, and MMG amplitude were assessed from the baseline and 0 week testing visits. Repeated measures ANOVAs were used to assess systematic error, and model 2,k (26) were used to calculate intraclass correlation coefficients (ICCS), standard errors of measurement (SEM), and minimal difference (MD) needed to consider a change as 'real' (29). The $95 \%$ confidence intervals for the means of the dependent variables were calculated with the studentized $t$-distribution. 


\subsubsection{Statistical analyses}

Muscle cross-sectional area was examined from the 0 week to 4 week testing visits using a paired samples $t$-test and the effect sizes for the paired $t$-tests were interpreted using Cohen's $d$. To determine the slope coefficients of the EMG amplitude versus torque relationships, separate linear regression analyses were performed on the individual EMG amplitude versus torque relationships from $10 \%-100 \%$ of MVIC at the 0 week and 4 week testing visits (Moritani and deVries 1979). In addition, separate linear regression analyses were performed on the individual MMG amplitude versus torque relationships from $10 \%-60 \%$ of MVIC at the 0 week and 4 week testing visits. This portion of the MMG amplitude versus torque relationship was selected based on previous investigations (Beck et al 2009, Stock et al 2010, DeFreitas et al 2011) that have reported that the MMG versus torque relationship increases linearly from $10 \%$ to $60 \%-80 \%$ of MVIC for the forearm flexors. The slope coefficients of the individual EMG and MMG amplitude versus torque relationships were examined across the 0 week and 4 week testing visits as described by Pedhazur (1997) and DeFreitas et al (2011). Briefly, a common regression coefficient is determined from the pooled sums of products and the pooled sums of squares between conditions. If the increment in the proportion of variance accounted for by the individual slope coefficients was statistically greater than the proportion of variability accounted for by the common regression coefficient, it was concluded that the slope coefficients between conditions were statistically different. All statistical analyses were performed using IBM SPSS v. 25 (Armonk, NY) and an alpha of $p \leq 0.05$ was considered statistically significant for all regression analyses. As recommended by Pedhazur (1997), an alpha of $p \leq 0.10$ was considered statistically significant for the individual slope coefficient analyses.

\section{Results}

\subsection{Reliability}

Table 2 includes the test-retest reliability and MD values from the baseline and 0 week measurements of concentric peak torque, MVIC, muscle crosssectional area, EMG amplitude, and MMG amplitude. There were no mean differences for baseline versus 0 week testing visits $(p>0.05)$ for any of the variables. The ICC values ranged from $0.719-0.948$ and the SEM values ranged from $3.8 \%-16.7 \%$ of the grand mean. 
Table 2. Test-retest reliability assessed from the baseline and 0 week testing visits for all subjects $(n=12)$.

\begin{tabular}{|c|c|c|c|c|c|c|c|c|}
\hline Variables & Baseline & O week & $p$-value & ICC & $I C C_{95 \%}$ & SEM & MD & Grand mean \\
\hline Muscle cross-sectional Area $(\mathrm{cm}$ & $5.96 \pm 0.52$ & $5.86 \pm 0.65$ & 0.345 & 0.904 & $0.517-0.972$ & 0.26 & 0.74 & 5.91 \\
\hline Concentric peak torque (Nm) & $18.5 \pm 4.3$ & $18.3 \pm 3.8$ & 0.812 & 0.915 & $0.699-0.975$ & 1.7 & 4.8 & 18.4 \\
\hline MVIC (Nm) & $20.2 \pm 6.0$ & $19.8 \pm 6.7$ & 0.701 & 0.948 & $0.820-0.985$ & 2.1 & 5.9 & 20.0 \\
\hline MVIC EMG amplitude $(\mu \mathrm{V})$ & $1115.2 \pm 315.6$ & $1160.5 \pm 414.2$ & 0.411 & 0.935 & $0.783-0.981$ & 76.7 & 220.2 & 1137.9 \\
\hline MVIC MMG amplitude $\left(\mathrm{m} \cdot \mathrm{s}^{-2}\right)$ & $0.54 \pm 0.27$ & $0.60 \pm 0.22$ & 0.191 & 0.926 & $0.731-0.979$ & 0.09 & 0.27 & 0.57 \\
\hline
\end{tabular}

Note: $p$-value (ANOVA for systematic error), intraclass correlation coefficient (ICC), ICC 95\% confidence interval (ICC95\%), standard error of the measurement (SEM), minimal difference (MD), maximal voluntary isometric contraction (MVIC), electromyography (EMG) and mechanomyography (MMG).

\subsection{Muscle cross-sectional area}

Muscle cross-sectional area increased significantly $(p<0.001 ; d=2.15)$ from 0 week (mean $\left.\pm \mathrm{SD}=5.86 \pm 0.65 \mathrm{~cm}^{2}\right)$ to 4 weeks $\left(7.42 \pm 0.80 \mathrm{~cm}^{2}\right)$ and exceeded the MD of $0.74 \mathrm{~cm}^{2}$ (Figure 2).

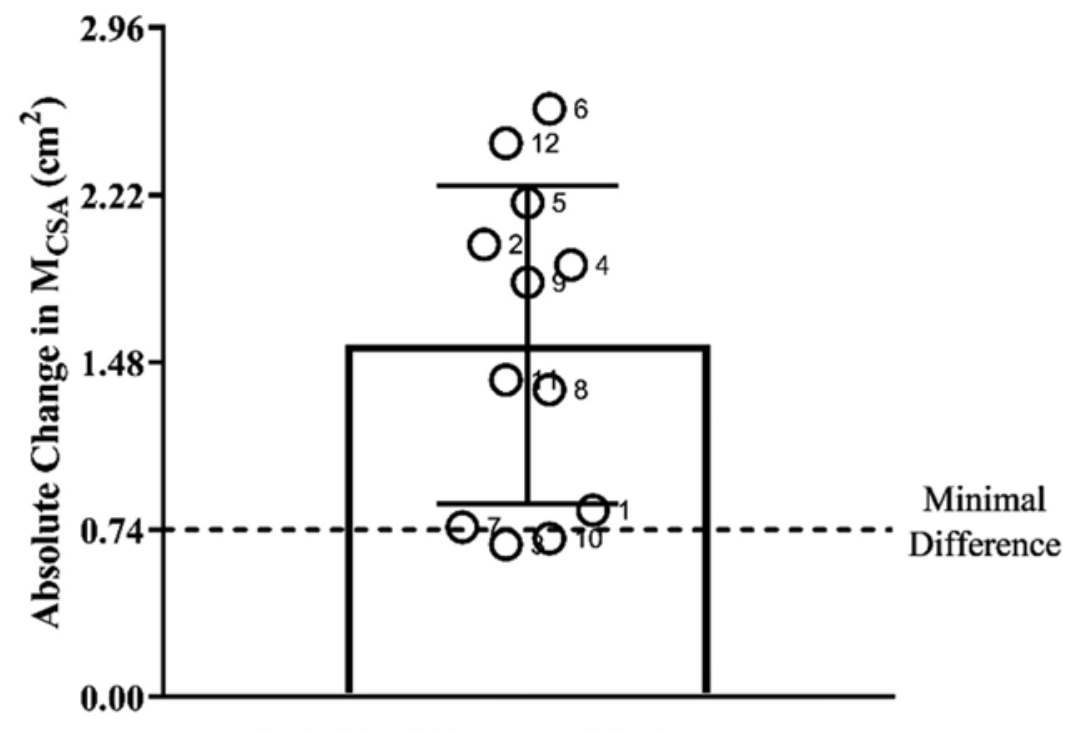

Individual Hypertrophic Responses

Figure 2. The individual subject responses as well as the mean \pm SD for muscle cross-sectional area (MCSA) from 0 week to 4 week testing visit. The MD needed for a change to be considered "real" is plotted and derived using standard error of measurement (SEM) values from the reliability data in Table 2 and using the equation, MD $=\mathrm{SEM} \times 21 / 2 \times \mathrm{df}$ (Weir 2005). Note. Subject 1 in Figure 1 is also Subject 1 in Tables 3 and 4 . This is true for all subjects. 
Table 3. The individual and mean slope and regression coefficients of the EMG amplitude versus torque relationships for 0 week and 4 weeks derived from the linear regression analyses for the incremental isometric muscle actions performed at $10 \%-100 \%$ of the 0 week MVIC torque.

\begin{tabular}{|c|c|c|c|c|c|}
\hline \multirow[b]{2}{*}{ Subject } & \multicolumn{2}{|l|}{0 week } & \multicolumn{2}{|c|}{4 week } & \multirow{2}{*}{$\frac{\text { Slope comparisons }}{p \text {-value }}$} \\
\hline & Slope $\left(\mu V \cdot N^{-1}\right)$ & $r^{2}$ & Slope $\left(\mu V \cdot N m^{-1}\right)$ & $r^{2}$ & \\
\hline 1 & 52.80 & 0.967 & 47.67 & 0.967 & 0.294 \\
\hline 2 & 74.12 & 0.922 & 63.67 & 0.962 & 0.274 \\
\hline 3 & 23.92 & 0.986 & 31.13 & 0.979 & $0.004^{b}$ \\
\hline 4 & 36.67 & 0.963 & 14.20 & 0.555 & $<0.001^{\mathrm{a}}$ \\
\hline 5 & 45.48 & 0.847 & 53.09 & 0.976 & 0.334 \\
\hline 6 & 43.49 & 0.963 & 25.14 & 0.758 & $0.003^{a}$ \\
\hline 7 & 56.91 & 0.963 & 35.19 & 0.760 & $0.004^{a}$ \\
\hline 8 & 60.59 & 0.942 & 65.32 & 0.920 & 0.624 \\
\hline 9 & 32.67 & 0.934 & 41.44 & 0.936 & $0.046^{b}$ \\
\hline 10 & 49.35 & 0.923 & 51.59 & 0.952 & 0.751 \\
\hline 11 & 98.53 & 0.932 & 70.33 & 0.939 & $0.012^{\mathrm{a}}$ \\
\hline 12 & 33.83 & 0.850 & 27.09 & 0.893 & 0.280 \\
\hline Mean & 50.70 & 0.990 & 43.82 & 0.959 & $0.023^{a}$ \\
\hline
\end{tabular}

a. Significant $(p \leq 0.05)$ decrease in the slope coefficient from 0 week to 4 weeks.

b. Significant $(p \leq 0.05)$ increase in the slope coefficient from 0 week to 4 weeks.

\subsection{EMG and MMG versus torque relationships}

The EMG amplitude versus torque relationships increased linearly from 10\%$100 \%$ of MVIC for all subjects (Table 3), but the MMG amplitude versus torque relationships in the present study increased linearly from 10\%-60\% of MVIC (Table 4) and plateaued between $60-90 \%$ of MVIC (Figures 3 and 4 , respectively). There was a significant ( $p=0.023 ; d=0.36$ ) mean decrease in the EMG amplitude versus torque relationship from the 0 week (50.70 \pm $\left.20.41 \mu \mathrm{V} \cdot \mathrm{Nm}^{-1}\right)$ to 4 week $\left(43.82 \pm 17.76 \mu \mathrm{V} \cdot \mathrm{Nm}^{-1}\right)$ testing visits. For the individual EMG amplitude versus torque relationships, there were significant $(p \leq 0.10)$ decreases in the slope coefficients from 0 week to 4 weeks for four of the 12 subjects, significant increases for two of the 12 subjects, and no changes in the slope coefficients for the remaining six subjects (Table 3 ). There was no significant ( $p=0.192 ; d=0.17$ ) mean change in the MMG amplitude versus torque relationship from 0 week $\left(0.018 \pm 0.009 \mathrm{~m} \cdot \mathrm{s}^{-2} \cdot \mathrm{Nm}^{-1}\right)$ to 4 weeks $\left(0.020 \pm 0.009 \mathrm{~m} \cdot \mathrm{s}^{-2} \cdot \mathrm{Nm}^{-1}\right)$. For the individual MMG amplitude versus torque relationships, there was a significant $(p=0.005)$ decrease in the slope coefficient from 0 week to 4 weeks for one of the 12 subjects, a significant ( $p=0.024$ ) increase for one of the 12 subjects, and no changes for 10 of the 12 subjects (Table 4). 
Table 4. The individual and mean slope and regression coefficients of the MMG amplitude versus torque relationships for 0 week and 4 weeks derived from the linear regression analyses for the incremental isometric muscle actions performed at $10 \%-60 \%$ of the 0 week MVIC torque.

\begin{tabular}{|c|c|c|c|c|c|}
\hline \multirow[b]{2}{*}{ Subject } & \multicolumn{2}{|l|}{0 week } & \multicolumn{2}{|c|}{4 week } & \multirow{2}{*}{$\frac{\text { Slope comparisons }}{p \text {-value }}$} \\
\hline & Slope $\left(m \cdot s^{-2} \cdot \mathrm{Nm}^{-1}\right)$ & $r^{2}$ & Slope $\left(m \cdot s^{-2} \cdot \mathrm{Nm}^{-1}\right)$ & $r^{2}$ & \\
\hline 1 & 0.016 & 0.675 & 0.021 & 0.900 & 0.436 \\
\hline 2 & 0.030 & 0.970 & 0.013 & 0.968 & $0.005^{a}$ \\
\hline 3 & 0.020 & 0.940 & 0.022 & 0.706 & 0.765 \\
\hline 4 & 0.009 & 0.928 & 0.016 & 0.883 & 0.211 \\
\hline 5 & 0.011 & 0.914 & 0.010 & 0.942 & 0.900 \\
\hline 6 & 0.016 & 0.885 & 0.009 & 0.907 & 0.371 \\
\hline 7 & 0.019 & 0.944 & 0.029 & 0.947 & $0.024^{b}$ \\
\hline 8 & 0.011 & 0.937 & 0.017 & 0.845 & 0.314 \\
\hline 9 & 0.024 & 0.971 & 0.037 & 0.750 & 0.168 \\
\hline 10 & 0.037 & 0.864 & 0.027 & 0.748 & 0.413 \\
\hline 11 & 0.009 & 0.789 & 0.023 & 0.808 & 0.101 \\
\hline 12 & 0.016 & 0.933 & 0.010 & 0.809 & 0.426 \\
\hline Mean & 0.018 & 0.980 & 0.020 & 0.988 & 0.192 \\
\hline
\end{tabular}

a. Significant $(p \leq 0.05)$ decrease in the slope coefficient from 0 week to 4 weeks.

b. Significant $(p \leq 0.05)$ increase in the slope coefficient from 0 week to 4 weeks.

\section{Discussion}

The present findings indicated that four weeks of BFR resistance training increased mean muscle cross-sectional area, and 10 of the 12 subjects exceeded the MD to be considered a 'real' change (Figure 2). The $26.6 \%$ mean increase in muscle cross-sectional area in the present study was consistent with previous investigations (Takarada et al 2002, Fujita et al 2008, Laurentino et al 2012, Yasuda et al 2013, Ellefsen et al 2015) that have reported similar mean increases (3.5\%-20.3\%) as a result of BFR resistance training. For example, Yasuda et al (2013) reported absolute mean increases of $1.7 \mathrm{~cm}^{2}$ $\left(14.7 \pm 1.0\right.$ to $\left.16.4 \pm 1.4 \mathrm{~cm}^{2}\right)$ in men that were larger than the $1.56 \mathrm{~cm}^{2}(5.86$ $\pm 0.65 \mathrm{~cm}^{2}$ to $7.42 \pm 0.80 \mathrm{~cm}^{2}$ ) for the women in the present study. In addition, Yasuda et al (2013) reported increases of 10.6-12.0\% and Takarada et al (2000) reported an increase of $20.3 \%$ in muscle cross-sectional area following 6-16 weeks of BFR forearm flexion resistance training at $30 \%-50 \%$ of 1 RM. For the leg extensors, increases of 3.5\%-7.0\% in muscle cross-sectional area have been reported following 1-12 weeks of BFR leg extension resistance training at 20\%-30\% of 1RM (Fujita et al 2008, Laurentino et al 2012, Ellefsen et al 2015). Thus, the present findings, in conjunction with previous 


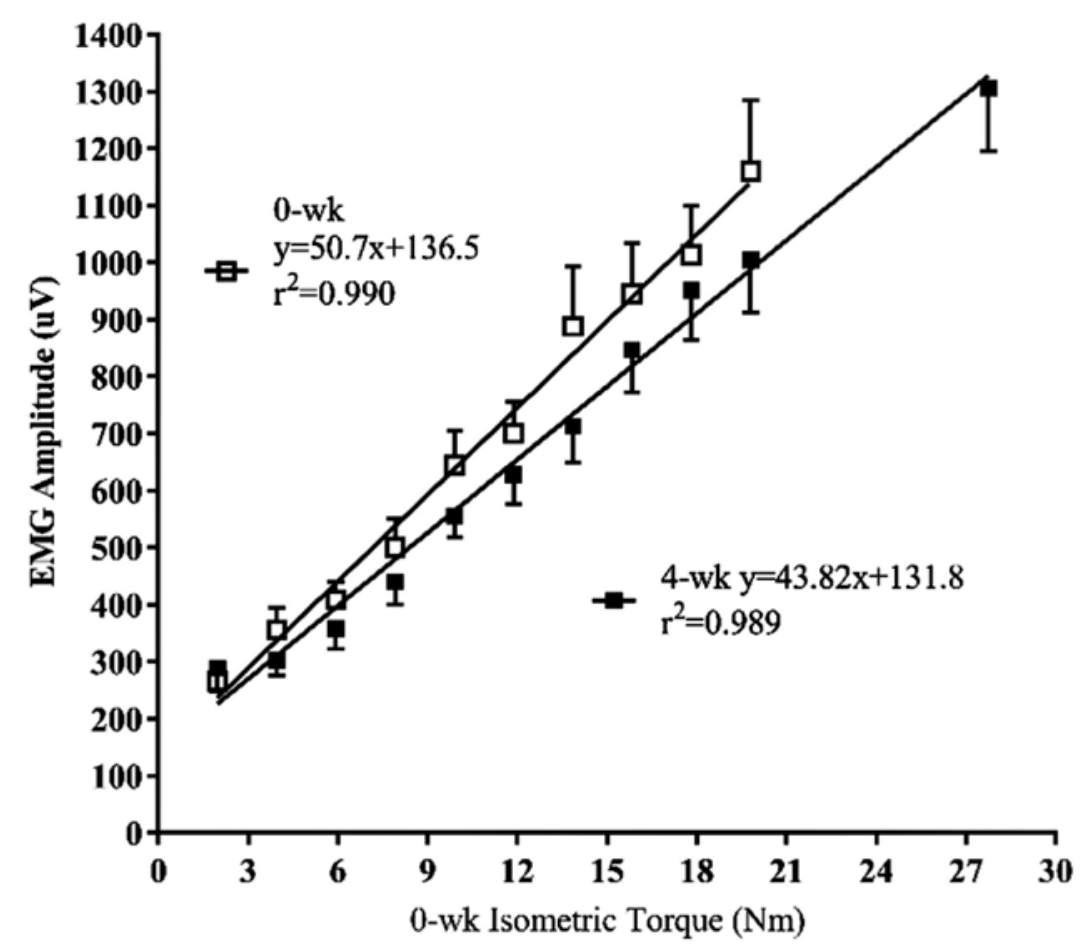

Figure 3. The mean responses for the integrated EMG amplitude values $(\mu \mathrm{V})$ across each of the incremental isometric muscle actions at $10 \%-100 \%$ of the 0 week MVIC) torque value performed in 10\% increments (Moritani and deVries 1979). At the 4 week testing visit, the subjects repeated the same procedures using their previously determined 0 week MVIC torque value, and the subjects also performed an additional MVIC to determine their 4 week MVIC torque value.

investigations (Takarada et al 2002, Fujita et al 2008, Laurentino et al 2012, Yasuda et al 2013, Ellefsen et al 2015) demonstrated that 1-16 weeks of BFR resistance training at $30 \%-50 \%$ of $1 \mathrm{RM}$ resulted in increases in muscle size.

Moritani and deVries (1979) used changes in the EMG amplitude versus force relationship to determine the time-course of the relative contributions of neural factors and hypertrophy to increases in strength. Specifically, a training-induced increase in maximal EMG amplitude was attributed to neural factors, while a decrease in the slope coefficient of the EMG amplitude versus force relationship reflected hypertrophy (Moritani and deVries 1979). As a result of eight weeks of forearm flexion resistance training at $66 \%$ of 1 RM, Moritani and deVries (1979) reported a training-induced decrease in the slope coefficient of the EMG amplitude versus force relationship and an increase in the anthropometrically estimated (skinfold corrected girth measure) arm cross-sectional area. The authors (Moritani and deVries 1979) hypothesized that the decrease in the slope coefficient of the EMG amplitude versus force relationship and concomitant increase 


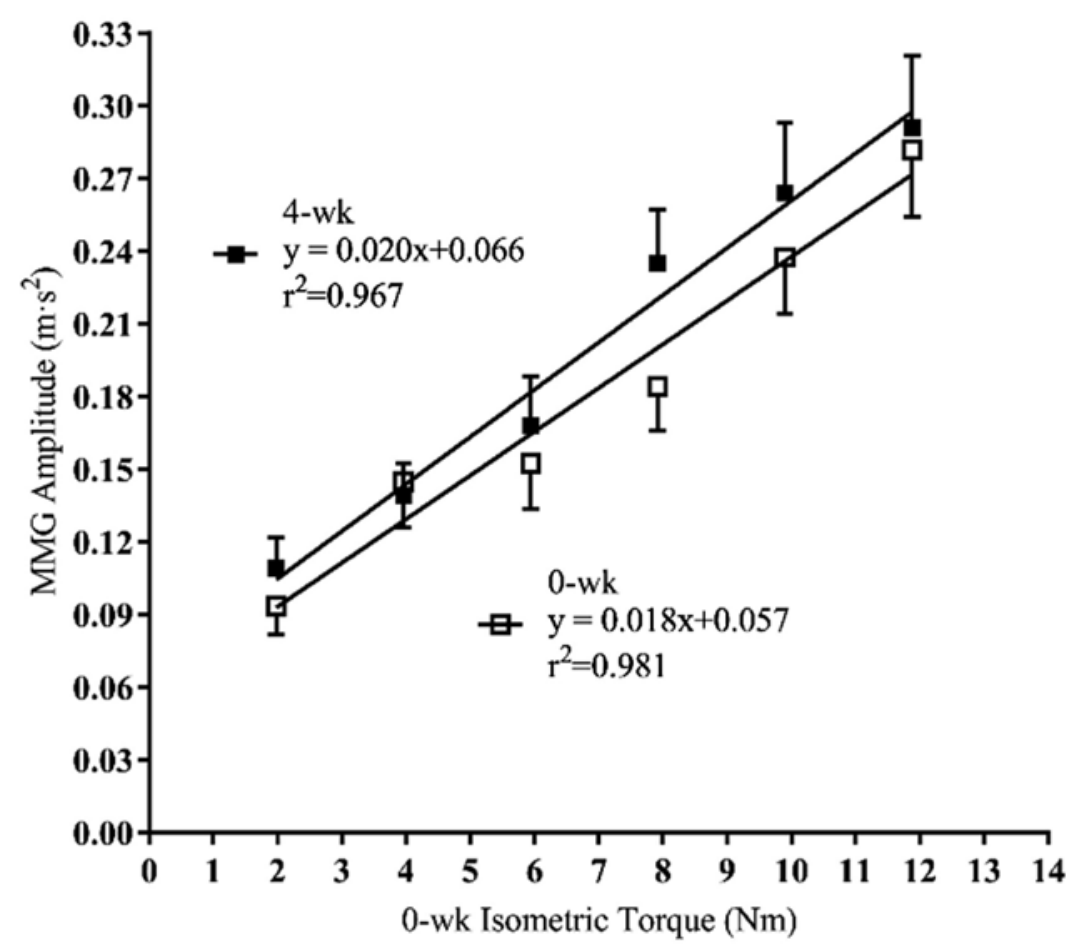

Figure 4. The mean responses for the MMG amplitude values (m.s-2) across each of the incremental isometric muscle actions at $10 \%-60 \%$ of the 0 week MVIC torque value performed in $10 \%$ increments (DeFreitas et al 2011). At the 4 week testing visit, the subjects repeated the same procedures using their previously determined 0 week MVIC value.

in arm cross-sectional area reflected a reduction in the number of motor units required to produce pretraining force levels as a result of muscle hypertrophy. DeFreitas et al (2012) applied the EMG-based mathematical model of Moritani and deVries (1979) to MMG and reported a mean decrease in the slope coefficient of the MMG amplitude versus force relationship for the leg extensors and a mean increase in total thigh muscle crosssectional area (DeFreitas et al 2011) as a result of eight weeks of bilateral leg press and leg extension resistance training at an 8-12 RM load. The decrease in the slope coefficient of the MMG amplitude versus force relationship was attributed to muscle hypertrophy because fewer motor units were required to produce pretraining force levels (DeFreitas et al 2012). Therefore, decreases in the slope coefficients of the EMG amplitude and MMG amplitude versus force relationships have been used to make inferences regarding the effects of resistance training on muscle hypertrophy (Moritani and deVries 1979, DeFreitas et al 2012).

The results of the present study indicated that there was a mean decrease in the slope coefficient of the EMG amplitude versus torque relationship 
(Figure 3) and a mean increase in muscle cross-sectional area of the biceps brachii (Figure 2). These findings supported the hypothesis of Moritani and deVries (1979) that muscle hypertrophy results in a reduction in the number of motor units required to produce pretraining force levels and, therefore, a decrease in the slope coefficient of the EMG amplitude versus torque relationship. In the present study, however, there was great variability in the slope coefficients of the EMG amplitude versus torque relationships for individual subjects (Table 3). For example, four subjects exhibited decreases in the slope coefficients for the EMG amplitude versus torque relationships and 'real' increases in muscle cross-sectional area. Two subjects, however, exhibited increases in the EMG amplitude slope coefficients and one of these subjects exhibited a 'real' increase in muscle cross-sectional area, and the EMG slope coefficients remained unchanged for six subjects, but five of these subjects exhibited 'real' increases in muscle cross-sectional area. Together, these findings indicated that the mean EMG amplitude versus torque relationship was sensitive to mean changes in muscle hypertrophy as a result of resistance training, but for eight of the 12 individual subjects, the application was not valid.

There was no mean change in the slope coefficient of the MMG amplitude versus torque relationship in the present study (Figure 4). In addition, one subject exhibited an increase in the slope coefficient for the MMG amplitude versus torque relationship, but a 'real' increase in muscle cross-sectional area, one subject exhibited a decrease in the MMG slope coefficient, and a 'real' increase in muscle cross-sectional area, and for ten subjects, the MMG slope coefficient remained unchanged, but eight exhibited 'real' increases in muscle cross-sectional area (Table 4 and Figure 2). Thus, these findings indicated that the slope coefficients of the MMG amplitude versus torque relationship were not sensitive to mean or individual increases in muscle hypertrophy.

The present findings were not consistent with those of DeFreitas et al (2012) who reported a mean decrease in the slope coefficient of the MMG amplitude versus force relationship and a mean increase in total thigh muscle cross-sectional area (DeFreitas et al 2011). The present study examined the MMG amplitude responses and muscle cross-sectional area from only the biceps brachii muscle. DeFreitas et al (2012) examined the MMG amplitude responses from the vastus lateralis only, but total thigh muscle crosssectional area included the leg extensors and leg flexors (DeFreitas et al 2011). Thus, in the present study, muscle hypertrophy and MMG amplitude responses were specifically related to only one muscle, while DeFreitas et al (2012) examined the MMG responses from the vastus lateralis, but muscle hypertrophy was related to the total thigh (DeFreitas et al 2011). Consequently, the mean percentage increase in muscle cross-sectional area of the biceps brachii in the present study was greater than that for total thigh 
muscle cross-sectional area of DeFreitas et al (2011) (26.6\% versus 9.6\%), but the mean absolute increase was considerably less $\left(1.56 \mathrm{~cm}^{2}\right.$ versus 13.9 $\mathrm{cm}^{2}$ ). Furthermore, in the present study, for the individual subject responses there was an increase, decrease, and no changes in the slope coefficients of the MMG amplitude versus torque relationships. DeFreitas et al (2012) reported that nine of the 21 subjects demonstrated no changes in the slope coefficients of the MMG amplitude versus force relationships. Thus, the combined results of the present study and those of DeFreitas et al (2012) indicated that for 19 of the 33 total subjects, there was no significant traininginduced decrease in the MMG amplitude versus force or torque relationship. Therefore, the present findings in conjunction with those of DeFreitas et al (2012) indicated that the MMG amplitude versus torque (or force) relationship was not sensitive to individual changes in muscle hypertrophy.

\section{Limitations}

The amplitude of the EMG and MMG signals were used to infer changes in muscle activation and motor unit recruitment, respectively. A number of anatomical, physiological, and non-physiological factors, however, can affect the EMG signal including subcutaneous tissue layer, amplitude cancellation, environmental noise, and electrode placement (Basmajian 1985, Keenan and Valero-Cuevas 2008, Farina et al 2004, 2014). For example, the amplitude of the surface EMG signal represents the algebraic summation of the activated motor units and their firing rates. Consequently, the absolute voltage recorded by surface EMG is inversely related to subcutaneous adipose tissue layer (Petrofsky 2008) and decreases proportionally with adipose tissue thickness (Nordander et al 2003). However, 12 weeks of resistance training of the upper arm had no effect on adipose tissue thickness in women as assessed by magnetic resonance imaging and skinfold measurements (Kostek et al 2007). Thus, it is unlikely that the EMG amplitude versus torque relationships in the present study were affected by training-induced alterations in subcutaneous adipose tissue thickness.

Amplitude cancellation describes the loss of information captured by surface EMG that occurs as a result of 'overlapping positive and negative phases of motor unit potentials cancel one another and reduce the amplitude of the signal.' (Keenan et al 2005, p 120) and amplitude cancellation increases with contraction intensity (greatest during maximal voluntary efforts) (Keenan et al 2005, Keenan and Valero-Cuevas 2008). Farina et al (2004) suggested that amplitude cancellation underscores the limitation when examining neural drive as a result of an intervention as assessed by the EMG amplitude versus torque relationship. Specifically, Farina et al (2004) suggested 'because of the many factors that can influence this relation (EMG amplitude versus 
torque)... this relation should be identified on a subject-by-subject and muscle-by-muscle basis.' (Farina et al 2004, p 1489). Consistent with the precautions outlined by Farina et al (2004), a strength of the present study was that the EMG amplitude versus torque relationships were all examined on a subject-by-subject basis for the biceps brachii muscle exclusively and each relationship was plotted and the subsequent strength and magnitude of those relationships were described for each subject.

Inconsistent placement of electrodes could also alter the EMG signal and subsequent EMG amplitude versus torque relationships. To control for the influence that electrode placement may exhibit on the EMG amplitude versus torque relationships, the bipolar electrode arrangement was consistently placed over the same location on the muscle for each subject throughout the training intervention (Farina et al 2004). The location was identified based on the recommendations of Barbero et al (2012) and a minimal interelectrode distance of $30 \mathrm{~mm}$ was used (the accelerometer was placed between the bipolar electrode arrangement). In addition, each waveform and power-density spectrum were examined for signal quality and environmental noise (i.e. $60 \mathrm{~Hz}$ ).

The MMG signal can be influenced by muscle stiffness, muscle temperature, the viscosity of the intracellular and extracellular fluids, and intramuscular fluid pressure (Stokes and Dalton 1991, Orizio 1993, Beck et al 2005). MMG amplitude is inversely related to muscle stiffness which is a function of force production (Ettema and Huijing 1994). Training-induced increases in muscle strength may result in greater muscle stiffness at lower submaximal intensities that could decrease the MMG amplitude versus torque relationship. In the present study, however, the MMG amplitude versus torque relationships were derived based upon 0 week strength values and determined from $10 \%-60 \%$ of the pre-training MVIC value as per the protocol of DeFreitas et al (2012). In addition, the MMG amplitude versus torque relationships increased linearly $\left(r^{2}=0.675-0.988\right)$ for all subjects from $10 \%-$ $60 \%$ at 0 week and 4 weeks.

The amplitude of the MMG signal increases proportionally with skin temperature (Mito et al 2007), but is inversely related to intramuscular fluid pressure which is function by intracellular and extracellular fluid concentrations (Sjogaard and Saltin 1982). Skin temperature and intramuscular fluid pressure increase as a result of exercise, particularly under fatiguing conditions. To reduce the influence that muscle temperature and intramuscular fluid pressure may exhibit, the MMG amplitude versus torque relationships were performed under nonfatiguing conditions and one to two minutes of rest were allowed between each of the randomized, incremental submaximal isometric muscle actions. In addition, the echo intensity function via ultrasound has been used to track changes in intramuscular fluid concentrations (Damas et al 2016). We have recently reported that 
there were no changes in echo intensity (intramuscular fluid concentrations) following 4 weeks of a BFR resistance training intervention (Hill et al 2018). Collectively, there are a number of confounding factors that may affect the interpretation of the EMG and MMG amplitude versus torque relationships as indicators of motor unit recruitment and muscle hypertrophy, but the methodological approaches in the present study were used to reduce the influence of these factors on the EMG and MMG signals. In the present study, torque was assessed during forearm flexion muscle actions that represent the collective force output of the biceps brachii, brachioradialis, and brachialis. Ultrasound, EMG, and MMG, however, were assessed from the biceps brachii muscle exclusively. Therefore, agonists muscles may have contributed to the changes in torque as a result of resistance training that may affect the subsequent ultrasound, EMG, and MMG responses of the biceps brachii muscle.

\section{Summary}

The results of the present study indicated that the EMG amplitude versus torque relationship was sensitive to group changes in muscle cross-sectional area during the early-phase of resistance training. There was, however, great variability for the individual EMG amplitude versus torque relationships that limits its application for identifying individual changes in muscle hypertrophy. The MMG amplitude versus torque relationship, however, was not sensitive to group or individual changes in muscle cross-sectional area after four weeks of resistance training. Thus, unlike the EMG amplitude versus torque relationship, the MMG amplitude versus torque relationship should not be used to examine early-phase (i.e. $<4$ weeks) changes in muscle hypertrophy.

Acknowledgments - This research was supported by the National Strength and Conditioning Association Doctoral Research Grant and NASA Nebraska Space Grant. All data are presented honestly, without fabrication, falsification, or data manipulation.

Author contributions - ECH was a substantial contributor to study concept and design, carried out data acquisition, analysis, and interpretation, and was the primary author. JLK, CMS, RJS and GOJ helped carry out data acquisition. TJH was the primary manuscript reviser and a substantial contributor to study concept and design. All authors approved the final version of this manuscript. 


\section{References}

Barbero M, Merletti R and Rainoldi A 2012 Atlas of Muscle Innervation Zones Understanding Surface Electromyography and its Applications (New York: Springer)

Basmajian J V and De Luca C J 1985 Muscles Alive: their Functions Revealed by Electromyography (Baltimore, MD: Williams \& Wilkins)

Beck T W, Defreitas J M and Stock M S 2009 The linearity and reliability of the mechanomyographic amplitude versus submaximal isometric force relationship Physiol. Meas. 30 1009-16

Beck T W, Housh T J, Cramer J T, Weir J P, Johnson G O, Coburn J W, Malek M H and Mielke M 2005 Mechanomyographic amplitude and frequency responses during dynamic muscle actions: a comprehensive review Biomed. Eng. Online 467

Counts B R, Dankel S J, Barnett B E, Kim D, Mouser J G, Allen K M, Thiebaud R S, Abe T, Bemben M G and Loenneke J P 2016 Influence of relative blood flow restriction pressure on muscle activation and muscle adaptation Muscle Nerve 53 438-45

Damas F, Phillips S M, Lixandrao M E, Vechin F C, Libardi C A, Roschel H, Tricoli V and Ugrinowitsch C 2016 Early resistance training-induced increases in muscle cross-sectional area are concomitant with edema-induced muscle swelling Eur. J. Appl. Physiol. 116 49-56

Defreitas J M, Beck T W and Stock M S 2012 Effects of strength training on mechanomyographic amplitude Physiol. Meas. 33 1353-61

Defreitas J M, Beck T W, Stock M S, Dillon M A and Kasishke P R II 2011 An examination of the time course of training-induced skeletal muscle hypertrophy Eur. J. Appl. Physiol. 111 2785-90

Devries H A 1968 'Efficiency of electrical activity' as a physiological measure of the functional state of muscle tissue Am. J. Phys. Med. 47 10-22

Ellefsen S et al 2015 Blood flow-restricted strength training displays high functional and biological efficacy in women: a within-subject comparison with high-load strength training Am. J. Physiol. Regul. Integr. Comp. Physiol. 309 R767-79

Ettema G J and Huijing P A 1994 Skeletal muscle stiffness in static and dynamic contractions J. Biomech. 27 1361-8

Farina D, Merletti R and Enoka R M 2004 The extraction of neural strategies from the surface EMG J. Appl. Physiol. 96 1486-95

Farina D, Merletti R and Enoka R M 2014 The extraction of neural strategies from the surface EMG: an update J. Appl. Physiol. 117 1215-30

Fujita T, Brechue W F, Kurita K, Sato Y and Abe T 2008 Increased muscle volume and strength following six days of low-intensity resistance training with restricted muscle blood flow Int. J. KAATSU Train. Res. 4 1-8 
Hill E C, Housh T J, Keller J L, Smith C M, Schmidt R J and Johnson G O 2018 Early phase adaptations in muscle strength and hypertrophy as a result of lowintensity blood flow restriction resistance training Eur. J. Appl. Physiol. 118 1831-43

Jenkins N D, Miller J M, Buckner S L, Cochrane K C, Bergstrom H C, Hill E C, Smith C M, Housh T J and Cramer J T 2015 Test-retest reliability of single transverse versus panoramic ultrasound imaging for muscle size and echo intensity of the biceps brachii Ultrasound Med. Biol. 41 1584-91

Keenan K G and Valero-Cuevas F J 2008 Epoch length to accurately estimate the amplitude of interference EMG is likely the result of unavoidable amplitude cancellation Biomed. Signal Process. Control 3 154-62

Keenan K G, Farina D, Maluf K S, Merletti R and Enoka R M 2005 Influence of amplitude cancellation on the simulated surface electromyogram J. Appl. Physiol. 98 120-31

Kostek M A et al 2007 Subcutaneous fat alterations resulting from an upper-body resistance training program Med. Sci. Sports Exerc. 39 1177-85

Laurentino G C, Ugrinowitsch C, Roschel H, Aoki M S, Soares A G, Neves M Jr, Aihara A Y, Fernandes Ada R and Tricoli V 2012 Strength training with blood flow restriction diminishes myostatin gene expression Med. Sci. Sports Exerc. 44 406-12

Loenneke J P, Kim D, Fahs C A, Thiebaud R S, Abe T, Larson R D, Bemben D A and Bemben M G 2016 The influence of exercise load with and without different levels of blood flow restriction on acute changes in muscle thickness and lactate Clin. Physiol. Funct. Imaging 6 734-40

Loenneke J P, Thiebaud R S, Fahs C A, Rossow L M, Abe T and Bemben M G 2013 Blood flow restriction does not result in prolonged decrements in torque Eur. J. Appl. Physiol. 113 923-31

Mito K, Kitahara S, Tamura T, Kaneko K, Sakamoto K and Shimizu Y 2007 Effect of skin temperature on RMS amplitude of electromyogram and mechanomyogram during voluntary isometric contraction Electromyogr. Clin. Neurophysiol. 47 153-60

Moritani T and Devries H A 1979 Neural factors versus hypertrophy in the time course of muscle strength gain Am. J. Phys. Med. 58 115-30 Moritani T and Devries H A 1981 Neural factors versus hypertrophy in the time course of muscle strength gain in young and old men J. Geront. 36 294-97

Nordander C, Willner J, Hansson G A, Larsson B, Unge J, Granquist L and Skerfving S 2003 Influence of the subcutaneous fat layer, as measured by ultrasound, skinfold calipers and BMI, on the EMG amplitude Eur. J. Appl. Physiol. 89 514-9

Orizio C 1993 Muscle sound-bases for the introduction of a mechanomyographic signal in muscle studies Crit. Rev. Biomed. Eng. 21 201-43

Pedhazur E J 1997 Multiple Regression in Behavioral Research: Explanation and Prediction (Fort Worth, TX: Harcourt Brace College Publishers) 
Petrofsky J 2008 The effect of the subcutaneous fat on the transfer of current through skin and into muscle Med. Eng. Phys. 30 1168-76 Sjogaard G and Saltin B 1982 Extracellular and intracellular water spaces in muscles in man at rest and with dynamic exercise Am. J. Physiol. 243 R271-80

Stock M S, Beck T W, Defreitas J M and Dillon M A 2010 An examination of the linearity and reliability of the electromyographic amplitude versus dynamic constant external resistance relationships using monopolar and bipolar recording methods J. Neurosci. Methods 194 94-101

Stokes M J and Dalton P A 1991 Acoustic myography for investigating human skeletal muscle fatigue J. Appl. Physiol. 71 1422-6 Takarada Y, Sato Y and Ishii N 2002 Effects of resistance exercise combined with vascular occlusion on muscle function in athletes Eur. J. Appl. Physiol. 86 308-14

Takarada Y, Takazawa H, Sato Y, Takebayashi S, Tanaka Y and Ishii N 2000 Effects of resistance exercise combined with moderate vascular occlusion on muscular function in humans J. Appl. Physiol. 88 2097-106 Weir J P 2005 Quantifying test-retest reliability using the intraclass correlation coefficient and the SEM $J$. Strength Cond. Res. 19 231-40

Yasuda T, Loenneke J P, Thiebaud R S and Abe T 2013 Effects of blood flow restricted low-intensity concentric or eccentric training on muscle size and strength PLoS One 7 e52843 